\title{
Analysis of Container Communication in Artificial Intelligence
}

\author{
${ }^{1}$ Raphael Duval Folsom \\ ${ }^{1}$ Division History and Natural Science, The University of Oklahoma, Norman, Oklahoma \\ 1duvalfolsom@hotmail.com \\ Article Info \\ Journal of Computing and Natural Science (http://anapub.co.ke/journals/jcns/jcns.html) \\ Doi: https://doi.org/10.53759/181X/JCNS202101007 \\ Received 10 October 2020; Revised form 10 November 2020; Accepted 25 December 2021. \\ Available online 05 April 2021. \\ (C)2021 Published by AnaPub Publications.
}

\begin{abstract}
With the rapid growth of international container transportation and the development trend of large-scale ships, there are deficiencies in ship utilization and transportation economy. More and more liner companies are actively building and optimizing container shipping network to improve service efficiency and reduce unit operating cost. The optimization model of container shipping network is established. Taking the minimum total cost of container shipping network as the objective, considering the constraints of shipping network, the immune algorithm is applied to solve the model, to determine the optimal container transportation network. Finally, two schemes are designed, and the simulation analysis results can select an optimal scheme, and the effectiveness of the proposed method is verified.
\end{abstract}

Keywords - Container transportation, Artificial Intelligence, Network optimization; Immune algorithm.

\section{INTRODUCTION}

With the development of international shipping industry, the throughput of container is increasing, and the proportion of suitable container cargo is increasing. Container transportation has gradually replaced the traditional mode of bulk cargo transportation and become the trend of world transportation development. The prosperity of container shipping industry puts forward higher requirements for its own management mode and network structure. Especially in recent years, due to the aggravation of international trade imbalance, the problem of empty container backlog and transportation has gradually become the bottleneck of the development of various shipping companies [1].

The world's largest producer of container cargo, and large liner companies have been rooted for many years. Foreign liner companies often call to open [2] the coastal carrying business of foreign-funded liner on different occasions. The so-called coastal carrying business usually refers to the domestic transportation of foreign trade containers between coastal ports of a country.

Port congestion will delay the liner voyage, lead to the departure can not be normal on time, the capacity of the route will also be affected. When the port congestion is serious, the original route and schedule of the liner will change, and the goods will be transported to the standby port for unloading, which will bring extra transportation costs. For the shipping industry, solving the problem of port congestion is a major task [3].

At present, scholars at home and abroad have carried out a lot of research on the optimization design of container shipping network. In order to solve the whole route stowage problem of container ships, the corresponding decomposition algorithm is designed to improve the efficiency of solving the optimization model [4]. At the same time, intelligent ant colony algorithm is designed to solve the model. Considering the limited time of ships in the hub port and the capacity of feeder ships, the feeder transportation routes of container ships are optimized. Considering the uncertainty of transshipment, demand and empty container transportation, the short cycle shipping network and container transportation route are optimized, and the influence of different routes on fuel consumption of container ships is analyzed.

Considering the uncertainty of cargo's time in port and taking the transportation time limit as the main constraint, the container liner route network is optimized. Based on the statistical data of marine transportation and port ships, the 
development and changes of shipping season and route are obtained. It is pointed out that shipping companies with bulk cargo and liquid transportation capacity are more attractive to the market. Considering the cost of carbon emissions, the hub and spoke transportation network of the port is optimized to solve the optimal traffic volume and capacity allocation. Considering the congestion of container port, the optimization model of hub and spoke shipping network is established to determine the reasonable hub port selection scheme [5].

In this paper, an immune algorithm-based container shipping model is proposed to simultaneously optimize the container transportation path, empty container allocation scheme, container ship service frequency and ship type configuration of port container shipping network.

\section{CONTAINER NETWORK MODEL}

\section{Model hypothesis}

The network transportation of container shipping is a complex process, so the following assumptions should be made for the design of maritime transportation network:

Hypothesis 1: the structure of container shipping network is relatively stable, and the influence of uncertain factors such as emergencies is not considered [6].

Hypothesis 2: the model does not consider the difference between the cost of heavy container, empty container and rental box.

Hypothesis 3: the container flow between all ports in the model is known, which can be predicted according to the throughput of each port and the economic level of hinterland.

\section{Analysis of container transportation cost}

The cost of shipping container transportation is the total cost of shipping company in the whole process of transporting containers from port to port, which is divided into ship cost and port cost. Ship cost refers to all kinds of expenses incurred by the ship in the process of transportation, including regular maintenance cost, fuel cost and capital cost; port cost refers to all kinds of use expenses of ships entering and leaving the port, including tonnage tax, berthing fee, pilotage fee, tugboat fee, loading and unloading fee, etc [7].

The ship cost consists of two parts: the Charter cost (maintenance cost and capital cost) and the fuel cost, which is calculated by

$$
C_{i j}^{S, m}=C_{i j}^{R, m}+C_{i j}^{F, m}
$$

where $C_{i j}^{S, m}$ is the ship cost of a shipping company with $m$ ship type; $C_{i j}^{R, m}$ is the charter cost of a shipping company; $C_{i j}^{F, m}$ is the fuel cost of container ship with $m$ ship type.

The charter cost of a single container ship with $m$ is a composite function of the daily charter cost and transportation time, as shown in equation (2).

$$
C_{i j}^{R, m}=C_{i j}^{r, m}\left\{\frac{d_{i j}}{24 v_{m}}+\frac{\left[\left(t_{i}^{h, m}+t_{j}^{h, m}\right) \cdot q_{i j}+t_{i}^{w, m}+t_{j}^{w, m}\right]}{24}\right\}
$$

where $C_{i j}^{r, m}$ is the daily charter cost of a single container ship of a shipping company; $v_{m}$ is the speed of the container ship; $t_{i}^{h, m}$ is the average handling time of a single container when the container ship is handling at the port node $i \in N$. $q_{i j}$ is the traffic volume of a pseudo single container ship, including container generation and transit volume; $t_{i}^{w, m}$ is the waiting time of container ships at port node $i \in N$.

The fuel cost of $m$-type container ship mainly includes fuel consumption and lubricating oil consumption, as shown in formula (3). 


$$
C_{i j}^{F, m}=\frac{\left(C_{i j}^{F u e l, m} R_{i j}^{F u e l, m}+C_{i j}^{L u b, m} R_{i j}^{L u b, m}\right) H P_{m} d_{i j}}{v_{m}}
$$

where $C_{i j}^{F u e l, m}$ is the fuel cost consumed by the ship; $R_{i j}^{F u e l, m}$ is the fuel consumption; $C_{i j}^{L u b, m}$ is the cost of lubricating oil consumed by the ship; $R_{i j}^{L u b, m}$ is the consumption of lubricating oil; $H P_{m}$ is the engine power of the container ship.

The port cost includes the cost of entering the port [11] (pilotage fee, shifting fee, mooring fee and berthing fee collectively referred to as entrance fee) and loading and unloading cost, as shown in formula (4).

$$
C_{i j}^{P, m}=C_{i j}^{l, m}+C_{i j}^{H, m}
$$

where $C_{i j}^{P, m}$ is the port cost, $C_{i j}^{l, m}$ is the cost of entering the port, $C_{i j}^{H, m}$ is the handling cost.

For container ships with m ship type, the total transportation cost from port node $i$ to port node $j$ is shown in equation (5).

$$
C_{i j}^{T, m}=C_{i j}^{S, m}+C_{i j}^{P, m}
$$

For the container shipping network $G(N, A)$, the total transportation cost of the network is shown in formula (6) (Zhao et al., 2019).

$$
C^{T}=\sum_{i=1}^{N^{S}} \sum_{j=1, j \neq i}^{N^{S}} \sum_{m=1}^{M} 48 \rho_{i j}^{m} \cdot C_{i j}^{T, m} \cdot \varphi_{i j}^{m} \cdot q_{k l}^{0} \cdot \delta_{k l}^{i j}
$$

where $N^{S}$ is the number of port nodes, $M$ is the number of container ship types; $\rho_{i j}^{m}$ is the density of $m$ container liner ships sailing from port node $i$ to port node $j . \varphi_{i j}^{m}$ is the decision variable of container ship type selection, $q_{k l}^{0}$ is the container production from port $k$ to port $l ; \delta_{k l}^{i j}$ is the decision variable of container shipping network optimization problem.

The objective function of the model is as follows (7).

$$
\min _{\delta_{k l}^{i l}, \varphi_{i j}^{m}} C^{T}
$$

The constraint conditions are listed as follows:

$$
\begin{gathered}
1 \leq \sum_{i=1}^{N^{S}} \sum_{j=1, j \neq i}^{N^{S}} \delta_{k l}^{i j} \leq E+1 \\
\sum_{j=1, j \neq i}^{N^{S}} q_{i j} \leq P_{i}
\end{gathered}
$$

Where $E$ is port number of container transshipment, $P_{i}$ is the annual limit carrying capacity of port node $i$.

\section{MODEL BASED ALGORITHM}

Immune optimization is one of the main algorithms of artificial immune system, and it is a widely used intelligent optimization algorithm. When the immune clonal algorithm is used to solve the problem, the antibody represents the solution of the problem. The algorithm evolves the antibody through the relevant immune clone and mutation operators, and finally finds the optimal solution of the maritime network optimization problem [8].

The basic process of immune clone algorithm is described as follows 
Step 1: The problem is transformed into antibody coding representation.

Step 2: The initialization of antibody population is to generate a certain number of antibodies

Step 3: The affinity of each antibody in the antibody population was calculated.

Step 4: The antibody with high affinity was cloned.

Step 5: The antibody was mutated.

Step 6: If the current solution meets the requirements, the algorithm [9] ends and the final result is output; otherwise, continue to step (3).

In the implementation of immune based maritime network optimization, several key technologies are described as follows.

\section{(1) Affinity function}

In immune algorithm, affinity function is used to evaluate the quality of antibody. According to the characteristics of the problem, the affinity function is defined as the number of ports, that is, if $x=\left[x_{1}, x_{2}, \cdots, x_{i}, \cdots, x_{n}\right]$ is the legal antibody (a possible optimal shipping route), $f(x)=\sum_{i=1}^{n} x_{i}$, otherwise take 0.

(2) Adaptive cloning

Clone operation is one of the main operations of immune optimization, which affects the convergence speed and performance of the algorithm [10]. In this paper, we use a mechanism of white adaptation cloning according to the size of affinity to ensure that the excellent antibody with high affinity will evolve to the next generation. The details are as follows:

Suppose that the selected $S$ antibodies were ranked in the order of affinity value as follows: $M_{1}(g), M_{2}(g), \cdots, M_{s}(g)$, and then the number of ntibodies produced to the $q_{i}$ clone of the $i$ th antibody $M_{i}(g)(1 \leq i \leq s)$ was as follows:

$$
q_{i}(t)=\operatorname{Int}\left(n_{i} \times \frac{f\left(M_{i}(g)\right)}{\sum_{j=1}^{s} f\left(M_{j}(g)\right)}\right)
$$

where $\operatorname{Int}(*)$ denotes the rounding up, $n_{t}\left(n_{t}>s\right)$ denotes clone control parameter, $f(*)$ denotes the calculation of affinity function.

The total number of antibody population produced by the $g$ generation clone was as follows :

$$
Q=N(g)=\sum_{i=1}^{s} q_{i}(g)
$$

(3) Mutation operator

Immune algorithm generates new antibodies by mutation operator. In this paper, the antibody coding adopts binary technology, so the specific mutation method is: for any antibody, take the random integer $1<i<n . x=\left[x_{1}, x_{2}, \cdots, x_{n}\right]$ mutates into a new antibody $x^{\prime}=\left[x_{1}, x_{2}, \cdots, x_{i-1}, \cdots, x_{i+1}, x_{n}\right]$, where $b_{i}=\bar{x}_{i}$.

(4) Antibody modification

Since the antibody mutation may produce illegal lysis, it is necessary to carry out antibody modification operation to legalize it. Based on the connection matrix, the antibody is traversed to find the connection matrix of the corresponding subgraph, and the node with the smallest deletion degree (i.e., the gene bit 1 changes to 0 ) is found, and the node becomes 
the legal antibody. The details are as follows: check the elements in $x$ one by one. If $x_{i}$ is equal to 1 , check whether the elements after $x$ equal to 1 have an edge with $x_{i}$. if there is no edge, the element changes from 1 to 0 .

\section{CASE STUDY}

The number of port nodes is taken as 20 , the number of hub ports is 4 , two hub port locations and port allocation schemes are confirmed, which are shown in figures 1 and 2.

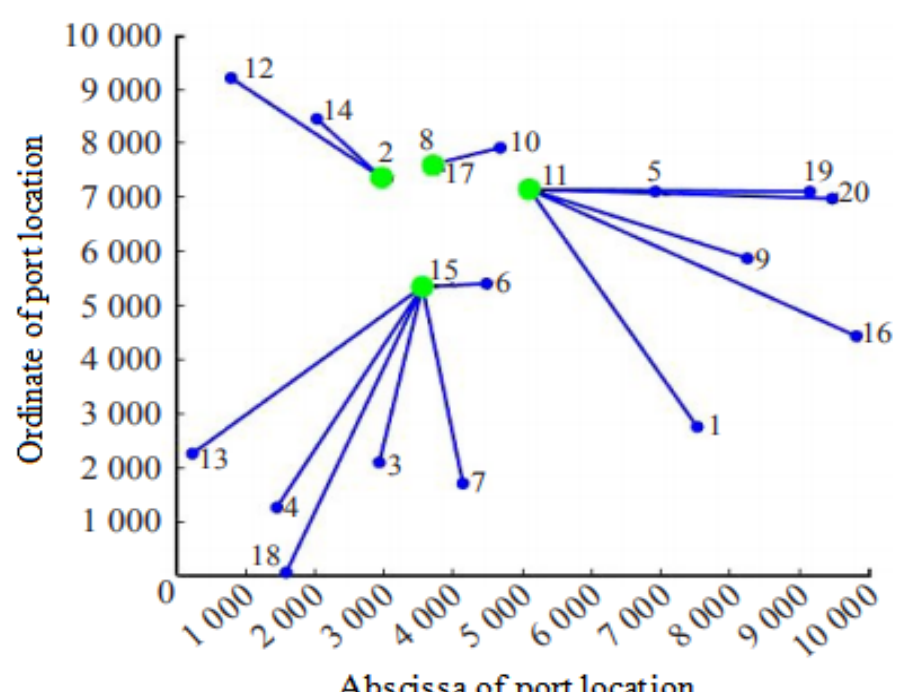

Fig 1. Diagram of scheme 1

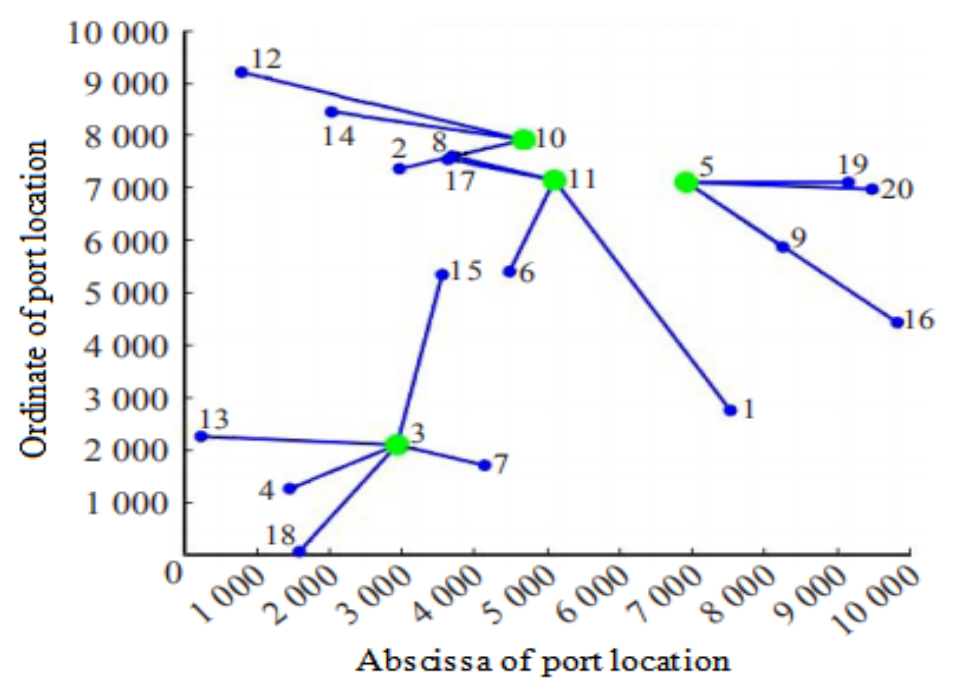

Fig 2. Diagram of scheme 2

The optimization results of comprehensive cost of container transportation network is listed in table 1. 
Table 1. Optimization results

\begin{tabular}{llll}
\hline & $\begin{array}{l}\text { Optimal } \\
\text { allocatio }\end{array}$ & $\begin{array}{l}\text { Direct } \\
\text { shipping } \\
\text { Scheme }\end{array}$ & \\
& $\mathrm{n}$ & $\begin{array}{l}\text { cost/Ten } \\
\text { million }\end{array}$ & $\begin{array}{l}\text { Computation } \\
\text { al time/h }\end{array}$ \\
& $\begin{array}{l}\text { cost/Ten } \\
\text { million } \\
\text { dollars }\end{array}$ & $\begin{array}{l}\text { dollars } \\
\end{array}$ & \\
\hline 1 & 4.33 & 5.25 & $0.92 \mathrm{~h}$ \\
2 & 4.82 & 5.33 & $0.89 \mathrm{~h}$ \\
\hline
\end{tabular}

The profit of scheme 2 about $16 \%$ higher than that of scheme, and the computational time is relatively small. Most of the containers are transported by direct transportation, but the long distance and small od volume will choose the transit mode. At the same time, the ships operating in the network are still mainly small and medium-sized containers, and large containers are only used for long-distance transportation. This is because large-scale container ships cannot reflect their scale benefits without a certain concentration of containers.

\section{CONCLUSIONS}

This research studies the optimization of the existing container shipping network by shipping enterprises and establishes a two-stage mathematical model of the optimization problem of the shipping network for maximizing profits. The immune optimization algorithm is used to solve the problem, and the effectiveness of the model is verified by an example. Finally, simulation experiments are carried out to analyze the cost of the two shipping schemes. The results show that the model can optimize the hub port selection and shipping route design of the existing maritime network and can provide reference for shipping enterprises to improve their own comprehensive service quality.

\section{References}

[1]. Ortony, J. Slack, and O. Stock, "Cognitive Science, Artificial Intelligence and Communication," Communication from an Artificial Intelligence Perspective, pp. 1-15, 1992.

[2]. G. Li and S. Zhi, "Research on Dynamic Container Truck Scheduling Based on Energetic Algorithm and MAS," 2010 International Conference on Artificial Intelligence and Computational Intelligence, Oct. 2010.

[3]. M. Vergeer, "Artificial Intelligence in the Dutch Press: An Analysis of Topics and Trends," Communication Studies, vol. 71, no. 3, pp. 373392, Mar. 2020.

[4]. T. Dereli and G. Sena Das, "A Hybrid Simulated Annealing Algorithm For Solving Multi-Objective Container-Loading Problems,” Applied Artificial Intelligence, vol. 24, no. 5, pp. 463-486, May 2010.

[5]. E. Y. C. Wong, H. S. C. Yeung, and H. Y. K. Lau, "Immunity-based hybrid evolutionary algorithm for multi-objective optimization in global container repositioning,” Engineering Applications of Artificial Intelligence, vol. 22, no. 6, pp. 842-854, Sep. 2009.

[6]. Y. Nishihara and Y. Ohsawa, "Communication Analysis focusing Negative Utterances in Combinatorial Thinking Games," Transactions of the Japanese Society for Artificial Intelligence, vol. 25, no. 3, pp. 485-493, 2010.

[7]. N. A. B. Gray, "Applications of artificial intelligence for organic chemistry: Analysis of C-13 spectra," Artificial Intelligence, vol. 22, no. 1, pp. 1-21, Jan. 1984.

[8]. E. Davis, "Knowledge and communication: A first-order theory," Artificial Intelligence, vol. 166, no. 1-2, pp. 81-139, Aug. 2005.

[9]. D. Murray-Rust and A. Smaill, "Towards a model of musical interaction and communication," Artificial Intelligence, vol. 175, no. 9-10, pp. 1697-1721, Jun. 2011.

[10]. I. Caragiannis and A. D. Procaccia, "Voting almost maximizes social welfare despite limited communication," Artificial Intelligence, vol. 175, no. 9-10, pp. 1655-1671, Jun. 2011.

[11]. B. A, "Informational Linguistics: Computer, Internet, Artificial Intelligence and Language," 2019 International Conference on Artificial Intelligence in Information and Communication (ICAIIC), Feb. 2019. 